\title{
Prevention of doxorubicin-induced alopecia by scalp cooling in patients with advanced breast cancer
}

\author{
JUSTINE E ANDERSON, JENNIFER M HUNT, IAN E SMITH
}

\begin{abstract}
Scalp cooling with gel packs was used to try to prevent alopecia in 31 patients being treated with doxorubicin (Adriamycin), 29 for advanced breast carcinoma and two for carcinoid tumour. Twenty-eight of the 31 patients tolerated the procedure well, and 22 of these had either no hair loss or only slight loss which remained acceptable and did not require a wig. The main factor limiting success was biochemical impairment of liver function, which occurred in nine patients; of these, six had severe or total alopecia despite scalp cooling. Conversely, the technique was successful in all 19 patients with normal liver function.
\end{abstract}

Carried out properly, this simple and effective technique greatly diminishes socially unacceptable alopecia associated with doxorubicin, and merits wider use.

\section{Introduction}

The anthracycline antibiotic doxorubicin (Adriamycin) is one of the most active cytotoxic agents currently used in cancer chemotherapy; it has a wide range of antitumour activity and is the most effective single agent in the treatment of advanced breast cancer. ${ }^{1}$ Its potential benefits, however, are offset by severe and usually total alopecia, which it causes in nearly all patients. ${ }^{2}$ The social and psychological consequences of this are obvious and have undoubtedly restricted its use.

Reports that scalp cooling might reduce the incidence of doxorubicin-induced alopecia ${ }^{3} 4$ have been supported by an American study suggesting that this technique prevents hair loss in some patients, especially when doses are less than $50 \mathrm{mg} .^{5}$

Royal Marsden Hospital, London SW3 6JJ

JUSTINE E ANDERSON, research sister, department of nursing research JENNIFER M HUNT, director, department of nursing research

IAN E SMITH, MD, MRCP, consultant medical oncologist
We therefore investigated the potential of scalp cooling using a new gel-pack technique in a series of patients receiving doxorubicin.

\section{Patients and methods}

Thirty-one patients were entered into the study; 29 were women with advanced breast carcinoma, and two were men with carcinoid tumour. Their ages ranged from 37 to 73 years (mean 51 years).

The caps used for scalp cooling were made up of $25 \times 10 \mathrm{~cm}$ polyethylene packs containing a gel which crystallises at $-15^{\circ} \mathrm{C}$ without freezing solid ( $3 \mathrm{M}$ brand); these were moulded together with waterproof tape to form a cap on a wig stand, which was then stored at $-20^{\circ} \mathrm{C}$ until required.

Before scalp cooling began the patient's hair was wetted, gauze and cotton-wool protectors were applied over the ears, and the head was covered with a wet crêpe bandage to reduce the amount of trapped air under the cap and thus improve conduction. The cooled cap was then applied to the bandaged scalp 15 minutes before treatment with doxorubicin and left in place for at least 30 minutes afterwards. The patient was supervised during the procedure, with pillows to support the head. Unless there were specific medical contraindications, patients were treated on an outpatient basis. Patients with advanced breast carcinoma were treated according to our current combination chemotherapy regimen, using $40 \mathrm{mg}$ doxorubicin intravenously on days one and eight of a 28-day cycle, in combination with either $2 \mathrm{mg}$ vincristine or $5 \mathrm{mg}$ vindesine. The two patients with carcinoid tumour were treated with $80 \mathrm{mg}$ doxorubicin intravenously at three-weekly intervals. All received at least two complete cycles of doxorubicin chemotherapy before assessment (total $160 \mathrm{mg}$ ). The range of doxorubicin given was $160-520 \mathrm{mg}$ (mean $320 \mathrm{mg}$ ).

Patients were assessed by the research nurse before each course of treatment. Response categories to scalp cooling were defined as: (a) no significant hair loss; (b) minor hair loss remaining socially acceptable and not requiring a wig; (c) severe hair loss requiring a wig; and (d) total alopecia.

\section{Results}

Twenty-eight of the 31 patients tolerated scalp cooling very well and without appreciable side effects. Three patients refused to continue treatment after an initial trial: one felt faint, and two felt too 
tired and ill to persevere. The first few patients complained that the cap felt heavy after 10 minutes or so, which was corrected in all subsequent patients by adequate head support with pillows. Nineteen patients complained of transient light-headedness immediately after the cap was removed; this settled spontaneously within a few minutes.

Twelve of the 28 patients who had a proper trial of scalp cooling experienced no substantial hair loss, though 11 lost pubic and axillary hair. A further 10 experienced only minor hair loss, not requiring a wig or head covering. Thus 22 out of 28 patients had socially acceptable hair protection. The remaining six patients had severe or total alopecia requiring a wig.

Before treatment eight patients had biochemical abnormalities of liver function (raised serum alanine transaminase, alkaline phosphatase, or gammaglucuronyl transferase activity) associated with hepatic metastases. A ninth patient developed abnormal liver function immediately after her first course of treatment. Six of the nine had severe or total alopecia despite scalp cooling, including one patient in whom cooling was continued for two hours after treatment with doxorubicin. The other three patients had minor hair loss not requiring a wig.

All 19 patients without biochemical evidence of impaired liver function had successful scalp cooling, either with no appreciable hair loss or with minor loss not requiring a wig.

Four patients had received six months of treatment (total doxorubicin dose $480-520 \mathrm{mg}$ ) and a further three five months of treatment (total $400 \mathrm{mg}$ doxorubicin). Five of the seven showed no appreciable hair loss, and two developed minor hair loss in their fifth month of treatment, but not severe enough to require a wig.

Fourteen of the 29 patients with advanced breast carcinoma achieved an objective tumour response (UICC criteria) during treatment. Nine of these patients had already had other chemotherapy; 13 out of 20 previously untreated patients achieved an objective response.

\section{Discussion}

These results confirm that this simple, well-tolerated technique for scalp cooling will prevent or very appreciably diminish doxorubicin-induced alopecia in most patients, with two important provisos. Firstly, we have no experience with doses higher than $40 \mathrm{mg}$ twice-monthly or $80 \mathrm{mg}$ three-weekly. Secondly, the procedure does not appear to be effective for most patients with biochemical evidence of abnormal liver function. This may be predicted on the basis of doxorubicin pharmacokinetics: in patients with normal liver function plasma doxorubicin concentrations fall rapidly after bolus injection during an initial distribution phase with the half life of 1.9 hours; impaired liver function is, however, associated with higher and noticeably more prolonged plasma concentrations, which remain raised for many hours. ${ }^{7}$ Thus a 30-minute period of scalp hypothermia after injection would effectively cover the period of highest plasma doxorubicin concentrations in normal patients, whereas cool- ing for up to two hours after treatment is ineffective in patients with impaired liver function.

We believe that details of the technique, though simple, are important for its success. In particular we think that wetting the hair and applying a wet crêpe bandage before the cooling cap play an important part in the high success rate for this technique by minimising trapped air and associated poor conduction. The relative merits of crushed ice and gel packs may be argued ${ }^{35}$; after an initial trial with crushed ice we preferred to use gel packs because they were simpler to prepare, less uncomfortable to the patients, and associated with less melting water during treatment. The most important problem was the weight of the cap; hence good head support with pillows was essential during treatment. Specially designed gel caps in perhaps two or three different sizes to fit directly on to the scalp would clearly be a useful development.

We conclude that this technique merits wider use in patients being treated with doxorubicin. It seems to us particularly attractive in patients with advanced breast cancer, for whom alopecia represents yet another result of mutilating treatment; it may also have an important part to play in encouraging the use of adjuvant doxorubicin for this disease, though the risk of protecting scalp micrometastases would need to be considered. Similar reservations would apply to any form of treatment with curative intent. Finally, further studies are required both with higher doxorubicin dosage and with other alopecia-inducing drugs.

We thank Farmitalia Carlo Erba for their generous research gran to JEA for this project and all the nursing staff at the Royal Marsden Hospital for their willing help.

Requests for reprints should be sent to: Jennifer M Hunt, Department of Nursing Research, Royal Marsden Hospital, London SW3 $6 \mathrm{JJ}$.

\section{References}

1 Tormey DC. Adriamycin in breast cancer. An overview of studies. Cancer Chemotherapy Reports 1975;6:319-27.

2 Benjamin RS. A practical approach to adriamycin toxicology. Cancer Chemotherapy Reports 1975;6:191-4.

${ }^{3}$ Edelstyn GA, MacDonald M, MacRae KD. Doxorubicin-induced hair loss and possible modification by scalp cooling. Lancet 1977;ii:253-4.

4 Timothy AR, Bates TD, Hoy AM. Influence of scalp hypothermia on doxorubicin related alopecia. Lancet 1980;i:663.

5 Dean JC, Salmon SE, Griffith KS. Prevention of doxorubicin-induced hair loss with scalp hypothermia. $N$ Engl f Med 1979;301:1427-9.

${ }^{6}$ Hayward JL, Rubens RD. Assessment of response to therapy in advanced breast cancer. Br $\mathcal{F}$ Cancer $1977 ; 35: 292-8$.

${ }^{7}$ Benjamin RS, Wiernik PH, Bachur NR. Adriamycin chemotherapyefficacy, safety and pharmacologic basis of an intermittent, single, highdosage schedule. Cancer $1974 ; 33: 19-27$.

(Accepted 7 November 1980)
ONE HUNDRED YEARS AGO The Royal College of Surgeons of Edinburgh has refused to follow the example of the Physicians, having thrown out, at its last quarterly meeting, a resolution "that the time had come when a change in the manner of admission to the Fellowship was desirable." Had Dr Andrew Wood survived a few weeks longer, it is more than probable that the result would have been different; for, strong Conservative as he was in college as well as in general politics, he held that reform was necessary; and had actually framed a report, which had been adopted by a special committee of that College, the basis of which was examination of candidates. No one knew better than he that, in whatever other directions future legislation bearing on medical matters might take effect, it would most certainly render all honorary titles unregistrable. And thus the Edinburgh College has lost the opportunity of doing gracefully ex proprio motu, what it will be sooner or later compelled to do by Act of Parliament. The sale of titles is an anachronism. The manufacture of Fellows at $£ 25$ per head is a vicious proceeding, which, directly and indirectly, affects the value of all Scotch qualifications. The general public cannot be expected to discriminate very nicely between honorary titles and qualifications to practise; and it therefore canno be wondered at that it should, in its ignorance, extend a feeling of suspicion to all the institutions of a country, one of whose principal medical corporations disposes of its honours for so much money. Should a Royal Commission be appointed, many of the hard facts which were stated during the discussion will appear in black and white; and no amount of special pleading will be able to wipe away the obloquy which must and will appertain. The arguments adduced in favour of maintaining the present state of things took almost entirely the commercial line: the College could not afford to throw away a great source of revenue, and so on; but we are thankful to know that there is a strong and rapidly increasing party which deprecates this tradesmanlike view of the question, and is strongly adverse to the continuance of such short-sighted policy. The motion was lost by only two votes; and we may therefore hope that, when the subject is again mooted, as it will assuredly be next year, the party of progress will be able to assert itself, and remove a stain which sullies the reputation of a corporation which has done, and is doing, good work. (British Medical fournal, 1881.) 